\title{
Recuerdos de la tierra que se secó. Un debate sobre la migración ambiental desde Chalcatzingo
}

\author{
Florencia Rivaud Delgado*
}

\begin{abstract}
Resumen
La categoría de migración ambiental permanece inmersa en un debate en el que se enfrentan quienes consideran que los problemas ecológicos son origen de ciertos flujos migratorios y quienes opinan que, incluso cuando su peso es incuestionable, no puede sobreponerse a otros factores, económicos y culturales, en las decisiones migratorias.
\end{abstract}

El presente artículo se propone desplazar el centro de este debate. Transitar de la búsqueda por categorizar a los migrantes ambientales hacia la de un método que incorpore lo ambiental al análisis de las migraciones. Para conseguirlo, sugiere adoptar un enfoque espacial, que permita observar el amplio campo de interacciones, materiales y simbólicas, que se teje entre una sociedad y su espacio.

Para poner en práctica este enfoque, la autora toma el caso de Chalcatzingo, un pueblo del México central en el que coinciden los tres elementos que los estudios sobre la migración ambiental ponen en relación: agricultura, degradación ambiental y emigración. Para analizar el papel de lo medioambiental entre los factores de expulsión, elabora una historia de la territorialidad del pueblo, en la que las "memorias de la tierra" se entrelazan con la historia agrícola del país y la del flujo migratorio en la región.

\section{Palabras Clave}

Migración ambiental; territorialidad; producción del espacio; memoria; crisis agraria.

\section{TITLE}

Memories of the land that dried up. Discussing environmental migration from Chalcatzingo

\section{Abstract}

The notion of environmental migration remains in the middle of a debate: those who consider ecological problems to be the origin of certain migratory flows are confronted with those who believe that even if this is unquestionable, it does not supercede other economic and cultural factors.

This article aims to shift the focus of the debate, from the search for a definition of environmental migrants, towards the search for a method that incorporates the environmental in the analysis of migrations. In order to achieve this, it proposes to adopt a spatial approach, allowing for the observation of a wide range of interactions, both material and symbolic, that are woven between a society and its space.

To put this approach into practice the author takes the case of Chalcatzingo, a town in central Mexico, in which three important elements from environmental migration studies come together: agriculture, environmental degradation, and emigration. In order to analyze the role of the environment among the expulsion factors, a history of the territoriality of the town is developed, in which the "memories of the land" are intertwined with the agricultural history of the country and the migratory flow in the region.

\section{KEYWORDS}

Environmental migration; territoriality; production of space; memory; agrarian crisis.

\section{*Florencia RI-} VAUD DELGADO, Doctora en Migraciones Internacionales e Integración Social por el Instituto Ortega y Gasset, maestra en Estudios po-líticos y Sociales y licenciada en Sociología por la Universidad Nacional Autó-noma de México. El principal eje de sus estudios es el uso de la memoria como herramienta metodológica para la comprensión de lo social. Este es el sentido de su libro, "El hacer cotidiano sobre el pasado. La reconstrucción de la memoria intersubjetiva en San José Lagunas" y de su tesis doc-toral, intitulada

"Recuerdos de la tierra que se secó. Migración y Memorias del paisaje en Chal-catzingo". Correo electrónico: para-

flora@gmail.com

\section{Recibido:}

2017-04-17

Aceptado:

2017-09-25

DOI: $10.15366 /$

relacionesinternacio nales2017.36.007 


\section{ntroducción}

En 1985, Essam El-Hinnawi propuso ante la ONU el reconocimiento de la categoría "refugiado ambiental" para llamar la atención sobre la necesidad de extender el derecho al asilo a quienes deben abandonar su lugar de residencia debido a que un problema medioambiental pone en riesgo o deteriora seriamente su calidad de vida ${ }^{1}$.

Aunque esta propuesta no fue incorporada al derecho internacional, la creciente preocupación por las consecuencias del calentamiento global alimentó el interés por estudiar los efectos de los problemas ambientales sobre los desplazamientos humanos. Nació de ahí la categoría de migración ambiental, dentro de la que se incluye tanto a las víctimas de desastres, como un tsunami o una sequía crónica, como a quienes deciden migrar en respuesta a un deterioro en su calidad de vida provocado por cambios repentinos o progresivos en el medio ambiente ${ }^{2}$.

Pese a su aparente claridad y a su impacto mediático, esta categoría ha encontrado fuertes detractores dentro de las disciplinas sociales, particularmente entre los especialistas en migraciones, quienes han señalado que, exceptuando el caso de los refugiados, determinar el origen ambiental de los flujos migratorios es difícil, ya que no pueden ignorarse otros factores -económicos, sociales y culturales- que incitan a la migración. Bajo esta óptica, la pertinencia teórica de la migración ambiental queda en entredicho³.

Debido a estas discrepancias, los estudios sobre el tema se han centrado en categorizar a los migrantes ambientales, diferenciándolos de los económicos en función del peso de los problemas ecológicos en las decisiones migratorias. Ejemplo de ello son el trabajo de Graeme Hugo $^{4}$, quien propone un continuum en el que se establece la influencia de lo ambiental en los flujos migratorios en función de su gravedad, y los modelos propuestos por Fabrice G. Renaud, Olivia Dun, Koko Warner y Janos J. Bogardi' ${ }^{5}$, quienes siguen una lógica similar, aunque incorporan otros factores, como las alternativas de sustento en el lugar de origen. También lo son aquellos que, analizando la migración en términos de la teoría de la nueva economía de las migraciones laborales, argumentan que las familias deciden enviar al extranjero a algunos de sus miembros para reducir los riesgos producidos por el deterioro ambiental ${ }^{6}$.

Los estudios que defienden la migración ambiental suelen basarse en el análisis

1 EL-HINNAWI, E., Environmental Refugees, United Nations Environment Programme, Nairobi, 1985, p.4.

2 Organización Internacional para las Migraciones OIM, Nonagésima cuarta reunión. Nota para las deliberaciones: La migración y el medio ambiente, 2007, MC/INF/288, p.3.

3 Para un análisis extenso sobre este debate ver SHURKE, A. Pressure points: environmental degradation, migration and conflict. Workshop on Environmental Change, Population Displacement, and Acute Conflict, June 1991. Ottawa: Peace and Conflict Studies Program, University of Toronto and The American Academy of Arts and Sciences, Cambridge, MA., 1993.

4 HUGO, G., Migration, development and environment, Draft paper for Research Workshop on Migration and the Enviornment: Developing a Global Research Agenda, Germany, 2008, consultado en http://www. populationenvironmentresearch.org, 22 enero de 2011.

5 RENAUD, F et.al, "Control, Adapt or Flee - How to Face Environmental Migration?", InterSecTions, 5, 2007, Bonn: United Nations University Institute for Environment and Human Security (UNU-EHS) consultado en www.un.edu, 3 de junio de 2011.

6 NAWROTZKI et.al., "Climate change as a migration driver from rural and urban Mexico", en Environmental Research Letters, Vol. 10, noviembre de 2015, pp. 1-9 y de HUNTER et.al. "Enviromental Dimensions of Migration", en Annual Review of Sociology, Vol.41, octubre de 2014, pp.377-397 
de la migración en sociedades agrarias y compartir un eje argumentativo: los problemas medioambientales dificultan la agricultura, mermando los ingresos de la población y obligándola a migrar. La investigación que aquí presento se desprendió del interés por poner a prueba esta tesis en el caso de México. De acuerdo con la Comisión Estadounidense para la Reforma Migratoria, aproximadamente 900.000 mexicanos son expulsados de tierras áridas y semiáridas cada año7. Este dato evidencia la importancia de analizar la relación entre medioambiente y migración en el caso mexicano, por lo que decidí hacer un estudio cualitativo que me permitiera comprenderla desde la perspectiva de un pueblo agrícola, con problemas ambientales, y migrante ${ }^{8}$.

Seleccioné con este fin a Chalcatzingo, un pueblo localizado en el estado de Morelos en el que coinciden los tres factores puestos en relación por los estudios sobre migración ambiental: agricultura, deterioro ecológico y migración. Elegí este pueblo por la claridad con que la historia del México agrícola se reflejaba en su paisaje y porque pertenece, en términos migratorios, a la región central. A diferencia de otras, como la Histórica o la Fronteriza, la región central no posee una arraigada tradición migratoria que explique el crecimiento y la persistencia del fenómeno. En los estados que la conforman la migración no comenzó a agudizarse hasta los años 90, lo que me permitiría observar con mayor claridad el papel de lo ambiental en la migración que en otras regiones del país, donde sería aún más difícil separar este elemento de otros, como el atractivo mercado laboral estadounidense.

Mi idea inicial era reconstruir la historia del paisaje del pueblo a través de las voces de sus habitantes con el objetivo de comprender qué tipo de vínculos establecían ellos entre los problemas ambientales y la migración. Sin embargo, al poco tiempo de haber iniciado el trabajo de campo, me di cuenta de que la relación entre los problemas ecológicos, el abandono de la agricultura y la migración era obvia, pero que leerla de manera lineal era reducir una compleja problemática a una explicación causal que, si bien no es errónea, es parcial: ni el abandono de la agricultura se explica únicamente por los problemas ecológicos ni la migración puede explicarse exclusivamente a través de la crisis agrícola.

Pensé, entonces, que la pregunta no era si la migración estaba producida por problemas ecológicos, sino cómo integrar lo medioambiental en el análisis de las migraciones. Con el fin de observar un campo de interacciones más complejo, decidí centrar la mirada en un plano más general: las relaciones entre una sociedad y su espacio. El presente artículo busca exponer cómo me aproximé a la migración ambiental a través de la perspectiva espacial, así como las reflexiones desprendidas del caso estudiado.

Comenzaré por presentar las herramientas teórico-metodológicas utilizadas. En un segundo momento, para contextualizar el estudio, describiré el paisaje de Chalcatzingo. Después, entraré de lleno en las palabras de sus habitantes, a través de las que reconstruiré la historia del desarrollo de la vida agrícola, los problemas ecológicos y la migración en el

7 RENAUD, F et.al, "Control..., op.cit., p.21.

8 Este artículo se desprende de mi tesis doctoral, intitulada "Memorias de la tierra que se secó. Migración y memorias del paisaje en Chalcatzingo".

9 DURAND, J. et. al., "Clandestinos. Migración México-Estados Unidos en los albores del siglo XXI", Universidad Autónoma de Zacatecas-Porrúa, México, 2003. 
pueblo. Finalmente, a modo de conclusión, explicaré los argumentos por los que considero que la perspectiva espacial puede contribuir a la comprensión de las relaciones entre migración y problemas ambientales.

\section{La territorialidad}

La perspectiva espacial se desprende de enfoques que, desde diversas disciplinas, han señalado que el espacio social es resultado de un proceso de apropiación, es decir, producto de una interacción en la que los humanos se "mundanizan" mientras humanizan al mundo ${ }^{10}$.

Henri Lefebvre explica esta relación de humanización/mundanización a partir de la idea de que el espacio es una producción social que se desenvuelve en dos dimensiones intrínsecamente relacionadas: una material y otra inmaterial. La dimensión material es resultado de la relación utilitario-funcional de las sociedades con su territorio, es decir, de aquellas acciones racionales dirigidas a satisfacer las necesidades biológicas y sociales de un grupo. La dimensión inmaterial es el proceso mediante el que el territorio se incorpora al entramado simbólico de una cultura, lo que permite que adquiera significación para los sujetos ${ }^{11}$.

Lefebvre subraya que la producción del espacio está siempre relacionada con las estructuras sociales, que determinan la lógica a partir de la que es ordenado, distribuido, modificado y simbolizado, generando una configuración espacial específica. La reconfiguración de estas estructuras implica un cambio en la manera de habitar el espacio, aunque las huellas -materiales y simbólicas- de las espacialidades anteriores permanecen, incorporadas o reinterpretadas, en las que les suceden. Debido a este carácter histórico-estructural el espacio funciona como un marco social, impregnado de contenidos simbólicos y habilitador de un conjunto de prácticas, que ordenan y cohesionan a la sociedad ${ }^{12}$. Es este marco el que aparece ante los sujetos como una estructura terminada, que parece imposible modificar y que condiciona sus movimientos, experiencias y discursos.

En el plano de la vida cotidiana, sin embargo, la rigidez de ese marco se difumina y da paso a un cuerpo flexible, "abierto, incompleto y en constante devenir"13. Esta plasticidad se debe a que en el transcurso de lo cotidiano, los sujetos llevan a cabo un conjunto de prácticas espaciales: acciones, rutinas, trayectorias que contribuyen a la reproducción y producción -material y simbólica- del espacio. Es a través de estos haceres cotidianos que los sujetos tienen la posibilidad de transformar o resignificar los espacios que los preceden, al cambiar la forma de utilizarlos, ordenarlos y atribuirles, a partir de su experiencia, nuevas cargas afectivas ${ }^{14}$. Y es que en la dimensión de la vida cotidiana el espacio estructurado es un espacio vivido, que se dibuja a través de los ojos de quienes lo habitan.

10 YORY, C., "Del espacio ocupado al lugar habitado: una aproximación al concepto de topofilia", en Serie ciudad y hábitat, Colombia, 2005, No.12.

${ }^{11}$ LEFEBVRE, H., The production of space, Blacwekk Publishing, UK, 1977.

12 HALBWACHS, M., Los marcos sociales de la memoria, Antrhopos, Barcelona, 2004.

13 MASSEY, D., "La filosofía y la política de la especialidad: algunas consideraciones", en Arfuch (Comp.): Pensar este tiempo: espacios, afectos, pertenencias, Paidós, México, 2005, pp. 102-128.

${ }^{14}$ DE CERTEAU, M., La invención de lo cotidiano. 1 Artes de hacer, Universidad Iberoamericana-ITESO, México, 2000. 
Como ya se ha mencionado, en la producción del espacio algunos elementos -materiales e inmateriales- se sedimentan y adquieren una forma durable, que no se transforma con facilidad ante los procesos sociales ${ }^{15}$. Gracias a esta durabilidad, el espacio puede operar como estructura, como un marco conformado por un ordenamiento, un conjunto de prácticas y un entramado simbólico que modelan la interacción, dando pie a la configuración de territorialidades.

La territorialidad es la dimensión espacial de la sociedad y los sujetos que emerge de la producción social del espacio. Involucra a los resultados materiales e inmateriales de este proceso, aquellos que permanecen a través de la historia y los que son imaginados, construidos o resignificados en el devenir cotidiano. Se refiere, a la vez, al espacio físico -resultado de la producción de una sociedad determinada- y a la amalgama en la que un conjunto de conocimientos prácticos y simbólicos sobre el entorno se unen con los vínculos afectivos que sustentan la identidad y el arraigo. Como consecuencia de la territorialidad, el espacio se convierte en "un proporcionador de sentido donde a la vez que orientamos nuestro andar estableciendo direcciones (orientaciones) definimos nuestra propia forma de ser a través de éstas ${ }^{\prime \prime 16}$.

\subsection{Memorias de la tierra}

La comprensión de un espacio social requiere, por lo tanto, de una suerte de historiografía capaz de poner en relación los cambios y permanencias del territorio, la estructura de la sociedad que lo habita y los universos simbólicos que se han desplegado sobre él. Además de permitir observar un amplio campo de relaciones, analizar el espacio de esta manera permite llevar la mirada del nivel macro de los procesos histórico-estructurales al nivel micro, ahí donde se hacen presentes los sujetos y resaltan los procesos simbólico-afectivos implicados en su producción.

Construí con este objetivo la categoría "memorias de la tierra". Como las 'narrativas de vida espacial' propuestas por Alicia Lindón, las memorias de la tierra son un "relato organizado y secuencializado espacio-temporalmente" sobre las experiencias vividas por un sujeto, elaborado en el contexto de una entrevista en profundidad en las que se busca que el sujeto narre los cambios ocurridos en un espacio a través de sus recuerdos sobre los lugares, las prácticas que desarrollaba en ellos y las sensaciones que le generaban ${ }^{17}$. En estos relatos se evidencia cómo el lugar "se hace parte de la experiencia ahí vivida, influye de alguna forma en la experiencia, le imprime una marca"18.

Sin embargo, a diferencia de las narrativas de vida espacial las memorias de la tierra parten de la idea de que los grupos poseen una memoria sobre su territorio, así como la

\footnotetext{
${ }^{15}$ SANTOS, MILTON., Por una geografía nueva, Espasa-Caple, España. (Milton Santos, 1990, p.154).

${ }^{16}$ YORY, CARLOS, Del espacio... op.cit. p. 51.

${ }^{17}$ Realicé la primera etapa del trabajo de campo en Chalcatzingo entre septiembre y diciembre de 2011. La segunda se desarrolló en las ciudades de San Diego y Nueva York, entre febrero y agosto de 2012. Hice un total 37 entrevistas a migrantes y no migrantes de Chalcatzingo. De ellas, 15 tuvieron lugar en la comunidad y 22 en Estados Unidos.

18 LINDÓN, A., De las geografías constructivistas a las narrativas de vida espaciales como metodologías geográficas cualitativas, en Revista ANPEGE, No. 4, pp.3-27, Brasil, 2008, p.19.
} 
que tienen sobre su propia historia ${ }^{19}$. Esta memoria es una construcción intersubjetiva. Construcción porque la memoria es entendida como un proceso en el que se representan, desde el presente, eventos e imágenes del pasado. Intersubjetiva porque, pese a ser una operación mental individual, es producto de las interacciones a través de las que incorporamos imágenes y narraciones sobre el pasado, así como criterios para seleccionar los elementos que se deben recordar u olvidar. Se trata, entonces, de una elaboración profundamente subjetiva, en tanto que depende de la percepción -y, por lo tanto, de las cualidades biológicas, psicológicas y afectivas-, y que, a la vez, se desprende de lo social, ya que está mediada por un conjunto de discursos que el sujeto interioriza y reproduce, pero también reflexiona y modifica ${ }^{20}$.

La noción de memoria intersubjetiva es una herramienta teórico-metodológica para acercarse a la memoria desde las disciplinas sociales, dejando atrás la dicotomía entre lo individual y lo colectivo, con el objetivo de observar cómo las sociedades elaboran su pasado y cómo esta elaboración incide en el hacer de lo social. Inscritas en este marco, las memorias de la tierra buscan reconstruir a partir de un conjunto de rememoraciones -entendidas como una producción intersubjetiva- la memoria de la relación que un grupo tiene con el espacio que habita.

El resultado, como puede esperarse, no es una secuencia fotográfica de los cambios ocurridos en el pueblo. Se trata, más bien, de un conjunto de narraciones sobre los espacios que se han dejado atrás, construido a partir del recuerdo de las rutinas a través de las que se habitaba y de las aventuras que irrumpían en ellas. Su valor heurístico no reside, por ende, en su precisión, sino en la claridad con la que expresan la forma en que los sujetos perciben su pasado, en la que también se hace visible cómo contemplan su presente e imaginan su futuro.

Las memorias de la tierra deben su nombre a que toman como eje a un elemento particular de la vida espacial: la agricultura -labor a la que los campesinos comúnmente se refieren como "trabajar la tierra"- y a la forma particular de percibir el espacio que se desprende de ella.

Estas narrativas me permitieron crear una serie de imágenes sobre cómo se ha modificado el territorio de Chalcatzingo. En ellas se hizo visible cómo fueron entretejiéndose los cambios ambientales, los problemas enfrentados por los agricultores y el surgimiento de la emigración en el pueblo. Para comprender este proceso desde una perspectiva espacial, haré una revisión histórica sobre los cambios estructurales ocurridos en el campo mexicano a lo largo del siglo XX, a la que entrelazaré las voces de los chalcas ${ }^{21}$, que me permitirán dar cuenta de cómo estos incidieron en su relación cotidiana con el espacio. Antes, es fundamental conocer el territorio estudiado.

\footnotetext{
${ }^{19}$ HALBWACHS, M., La memoria colectiva, Prensas Universitarias de Zaragoza, España, 2004.

${ }^{20}$ WERTSCH, J., DEL RÍO P., ÁLVAREZ A., La mente sociocultural: aproximaciones teóricas y aplicadas, Fundación Infancia y Aprendizaje, España, 1997.

${ }^{21}$ Si bien "chalcatzinga" es su gentilicio, los nacidos en Chalcatzingo comúnmente se refieren a su pueblo como "Chalca" y a ellos mismos como "chalcas".
} 


\section{Chalca}

Chalcatzingo (ver figura 1) se ubica en el Oriente del Estado de Morelos, un área de unos 70 $\mathrm{km}^{2}$ que desciende en una suave pendiente desde el Popocatépetl. Jantetelco, municipio al que pertenece, se encuentra en la parte más baja, conocida como la tierra caliente porque sus temperaturas contrastan con las frías tierras cercanas a la cima. La región está vertebrada por el río Amatzinac, que nace de las nieves del volcán y la atraviesa perdiéndose por profundas cañadas.

La tierra caliente es una extensa llanura en la que sobresalen tres cerros: el Peñón, el Tenango o Gordo y el Cantera o Delgado, a cuyos pies se asienta Chalcatzingo. Tiene un clima árido y semiseco, con un suelo -"vertisol pélico con textura fina y fase pedregosa"- favorable para la agricultura, pero de difícil labranza y muy proclive a la erosión ${ }^{22}$. Durante casi todo el año, una gama de ocres predomina en la vegetación y en la tierra. Este paisaje, en el que en los años 70 se rodaron varias películas del viejo oeste, contrasta con el esplendor de la época de lluvias, cuando los árboles sorprenden con sus flores.

El pueblo llamó mi atención desde el primer momento por la claridad con que la historia agraria del país se refleja en su territorio. Al sur, al piedemonte de los cerros, están los restos del Chalcatzingo precolombino, hoy convertidos en zona arqueológica. Hacia el oeste, el casco de la hacienda Santa Clara Montefalco, que dominó esas tierras desde la Colonia hasta el Porfiriato. Por lo cerros, los chalcas aún reconocen las cuevas donde se refugiaban los revolucionarios y sobre las tierras, que hoy, agotadas, producen maíz y sorgo, se proyectan las memorias del pueblo agrícola que fue hasta los años 90, cuando la gente empezó a migrar.

Figura 1. Morelos, la región Oriente y Chalcatzingo ${ }^{23}$

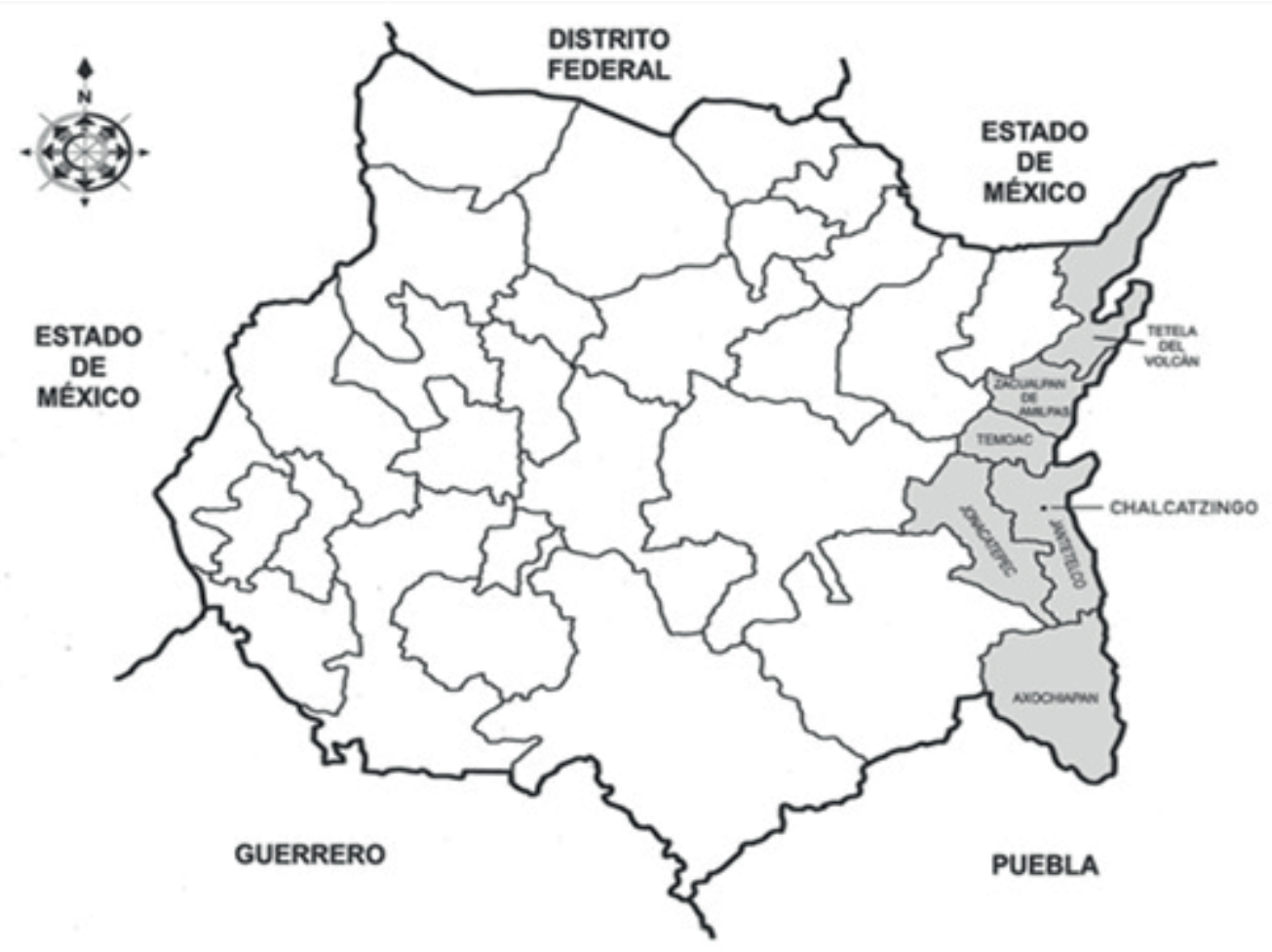

22 GUERRERO, M.A, Suelos agropecuarios del estado de Morelos, CRIM, México, 1993.

${ }^{23}$ Elaboración propia. 
Con 2, 449 habitantes en $2010^{24}$, Chalcatzingo aún conserva la atmósfera de un lugar pequeño, en el que prevalece el ritmo pausado de las caminatas y en el que la gente se saluda con una amplia sonrisa al cruzarse por la calle.

El pueblo se organiza en torno a una plaza central, en la que conviven las autoridades políticas -la comisaría ejidal-, la iglesia y el comercio informal. De ella se desprenden calles trazadas en una imperfecta cuadrícula. Al igual que los coches, que en al acercarse a la plaza quedan presos de un injustificado tráfico, las casas, mayoritariamente "de material", están altamente concentradas en el centro y más bien dispersas en la periferia. Desde la calle, son muros en los que de vez en cuando se asoma una pequeña ventana. Bardas y rejas cuya función aislante se suaviza por las puertas entreabiertas que permiten a los conocidos entrar al grito de "ibuenas tardes!".

Aunque el $40.92 \%$ de la Población Económicamente Activa se emplea en el sector primario ${ }^{25}$, basta echar un vistazo al pueblo para comprender que la agricultura no es el centro de su vida económica. Se nota en la poca vida de sus tierras, en la multiplicación de pequeños negocios -abarrotes, ferreterías, papelerías y hasta un improvisado cine- y en la abundancia de casas vacías o a medio construir. "Casas tristes", síntoma inconfundible de la migración ${ }^{26}$.

El paisaje actual de Chalcatzingo permite suponer que su migración podría estar relacionada con factores ambientales. Además de abandonadas, las tierras lucen secas y polvorosas, los cerros carecen de vegetación y el río Amatzinac tiene un humilde caudal. Esta percepción coincide con los diagnósticos ambientales hechos para el estado de Morelos, que señalan que el $80 \%$ del territorio forestal ha sido arrasado por el desarrollo urbano-industrial, la agricultura y el pastoreo, por lo que sus tierras están erosionadas y se presentan sequías interestivales ${ }^{27}$. A esto se suman otros factores de riesgo ambiental, como la escasez de agua generada por la sobreexplotación y la inocuidad, es decir, el uso indiscriminado de agroquímicos ${ }^{28}$.

Los chalcatzingas también asocian el inicio de la migración en el pueblo con una crisis ambiental que, según las memorias de la tierra, se desató en los años ochenta. Para analizar las características de esta crisis y su relación con los problemas migratorios, es fundamental conocer la historia de la territorialidad del México rural.

24 INEGI, Archivo histórico de censos en http://www3.inegi.org.mx/sistemas/productos/default.aspx?c=265\&s=in egi\&upc $=702825003963 \& p f=$ Prod $\& e f=\& f=2 \& c l=0 \& t g=0 \& p g=0$, consultado el 3 de marzo de 2013.

25 Conapo, Conteo nacional de población y vivienda 2010, en www.conapo.gob.mx, consultado 5 de mayo 2013.

${ }^{26}$ Zavella, P., I'm Neither Here Nor There: Mexican's Quotidian Struggles with Migration and Poverty, Duke University Press, EU, 2011.

27 OSWALD, U. y TRUJILLO, F., "Del Holoceno al Antropoceno: evolución del ambiente de Morelos", en Crespo (Dir), Historia de Morelos, tierra, gente, tiempos del Sur, Morales LG (Coord), tomo I, Historiografía, territorio y región, UAEM/ LI Legislatura del Congreso del Estado de Morelos, México, 2012.

${ }^{28}$ SAGARPA, Informe del diagnóstico rural del estado de Morelos, México, 2014, consultado en http://www.faoevaluacion.org.mx/pagina/documentos/sistemas/eval2014/resultados2014/PDF2/MOR/Diagnostico_Rural_ MORELOS.pdf, 3 de diciembre de 2017. 


\section{La territorialidad agrícola}

El Chalcatzingo agrícola que precedió al inició de la migración comenzó a gestarse tras la Revolución Mexicana (1917/1920), pero antes de comenzar este proceso, el Oriente del Estado de Morelos había tenido otras configuraciones territoriales que es importante tener en mente.

Entre los años 700 y 500 a.C., fue la ciudad más importante de la región, en gran medida gracias a la infraestructura que desviaba las aguas del Amatzinac hacia los cultivos de algodón, tomate, amaranto, chile y maíz. Se sabe que la ciudad comerciaba en el Valle Central y con los pueblos de ambas costas y que, pese a su poder económico, cayó antes de la Conquista. Como en muchas ciudades del México prehispánico, el declive pudo deberse a problemas ambientales asociados al crecimiento poblacional, como la carencia de agua y el agotamiento de las tierras ${ }^{29}$.

La llegada de los españoles supuso el inicio de una nueva época. El territorio fue dividido en enormes haciendas que se especializaron en caña de azúcar. Además de sus productos, los conquistadores impusieron nuevas técnicas agrícolas que aumentaron el tamaño y la intensidad de los cultivos. También introdujeron animales de trabajo y transporte, que rumiaron la cubierta forestal, dejando grandes extensiones de tierra erosionada e inútil para la siembra ${ }^{30}$. Este periodo se prolongó hasta el fin del Porfiriato (1911). Durante esos largos años, Morelos se consagró como el tercer productor mundial de caña de azúcar, después de Hawái y Puerto Rico ${ }^{31}$.

\subsection{Del ejido al mercado}

En 1920, la Revolución mexicana entregó las tierras a quienes las trabajaban. Para desarticular el modelo hacendario, se creó la propiedad ejidal, a través de la que el Estado concedía a los campesinos el usufructo de una parcela, pero con ciertas condiciones: debía ser cultivada por el titular y no podía mantenerse ociosa, venderse, alquilarse ni usarse como garantía.

En el ejido se veía, también, un medio para fomentar el surgimiento de una agricultura a pequeña escala, que diera arraigo y seguridad a la población rural y se convirtiera en el motor del crecimiento económico del país. Inició así una nueva era en la territorialidad chalcatzinga, cuyo eje era la agricultura y su protagonista natural el maíz, que garantizaba la alimentación de los campesinos y les permitía generar excedentes para la venta.

Durante los primeros años de postguerra, los chalcas sobrevivieron gracias al maíz y los huertos, en los que sembraban árboles frutales y plantas medicinales. Sus ingresos eran mínimos, pero suficientes para adquirir los productos básicos en los mercados locales, que funcionaban principalmente mediante el trueque. La situación comenzó a cambiar en los años treinta, cuando el gobierno tomó las riendas del desarrollo y puso en marcha el modelo de sustitución de importaciones. Bajo este esquema, el campo debía cumplir tres funciones:

\footnotetext{
${ }^{29}$ ARANA, R., "Classic and Postclassic Chalcatzingo", en GROVE, D., (ed), Ancient Chalcatzingo, University Texas Prees, E.U., 1987, pp. 387-399

30 ÁVILA, H., Aspectos históricos de la formación de regiones en el estado de Morelos: desde sus orígenes hasta 1930, CRIM-UNAM, México, 2001, p.16.

${ }^{31}$ GILLY, A., La revolución interrumpida, Era, México, 1971, p. 84.
} 
producir alimentos baratos, ser fuente de mano de obra y consumir. Contaba para ello con el apoyo del Estado que, además de promover el desarrollo rural mediante infraestructura y educación, había creado ya las primeras instituciones de crédito agrario.

Apoyados por los créditos estatales, los chalcatzingas incursionaron en cultivos comerciales, como sorgo, cacahuate y arroz. Ya que no estaban dispuestos a dejar de sembrar maíz, extendieron las zonas de cultivo y abandonaron gradualmente el periodo de descanso, que permitía a las tierras recuperar sus nutrientes.

Entre 1930 y 1960, la población de México dobló su tamaño y la de Morelos prácticamente se triplicó (ver tabla 1). El periodo de crecimiento demográfico coincidió con un boom económico sostenido en el desarrollo industrial, que el gobierno había impulsado para aprovechar el vacío en la producción estadounidense producido por la Segunda Guerra Mundial. Entre 1940 y 1960 las relaciones comerciales con Estados Unidos eran excelentes y el mercado interno crecía, ya que la industrialización catalizó el proceso de urbanización. La bonanza en estas décadas fue tal, que son conocidas como "el milagro mexicano".

La maquinaria estatal de apoyo al campo continuó fortaleciéndose durante el milagro. Se crearon fábricas de tractores, herramientas, agroquímicos y semillas; aumentaron los subsidios, se congelaron los precios de los granos básicos y se ensancharon los créditos a la producción. Esta estructura, a través de la que el Estado apuntalaba a la frágil economía campesina y, a la vez, encauzaba la producción hacia los intereses nacionales, se volvió fundamental para la apropiación del espacio rural.

Tabla 1. Crecimiento de la población 1900-2010 32

\begin{tabular}{|c|c|c|}
\hline Año & México & Morelos \\
\hline 1930 & 16552722 & 132068 \\
\hline 1940 & 19653552 & 182711 \\
\hline 1950 & 25791017 & 272842 \\
\hline 1960 & 34923129 & 386264 \\
\hline 1970 & 48225238 & 616119 \\
\hline 1980 & 66846833 & 947089 \\
\hline 1990 & 91158290 & 1442662 \\
\hline 2000 & 95753396 & 1502728 \\
\hline 2010 & 112336538 & 1777227 \\
\hline
\end{tabular}

En Morelos, la explosión demográfica supuso un incremento gradual de la presión sobre el campo y una consecuente pérdida de su productividad. En los cincuenta, las tierras del Oriente estaban tan agotadas que una parcela trabajada sin descanso durante dos años tenía el mismo rendimiento que cuando se respetaba el periodo de barbecho ${ }^{33}$.

\footnotetext{
32 Elaboración propia con datos del Archivo histórico de Censos Población y Vivienda (INEGI).

33 WARMAN, A., ... Y venimos a contradecir. Los campesinos de Morelos y el estado nacional, Ediciones de la casa Chata, México, 1976, p.217.
} 
Resulta llamativo que a pesar de las dificultades de aquellos años, la migración no se convirtió en una estrategia habitual en el pueblo. Esto, pese a que aquellos fueron los años del programa Braceros, que operó con algunas interrupciones entre 1942 y 1965, empleó a miles de mexicanos y, como lo demuestran los estudios de Douglas Massey, permitió la sedimentación del flujo migratorio en aquellas zonas de México que constituyen la región Histórica por su alta tradición migratoria ${ }^{34}$. Únicamente algunos chalcas se aventuraron al norte en aquellas décadas $y$, según recuerdan, regresaron a sus casas a los pocos meses, para volver a sembrar y dejar aquella experiencia en el olvido.

En el Oriente, aunque los subsidios y créditos agrarios llegaban a cuentagotas -ya que se dirigían principalmente a las tierras de riego del norte del país ${ }^{35}$ - los campesinos hicieron frente a la crisis con nuevos cultivos. Los pueblos de la tierra caliente sembraron arroz, pepino y jitomate; los de la tierra fría, aguacate y durazno ${ }^{36}$.

Al poco tiempo, los pueblos de la cuenca alta del Amatzinac aumentaron su consumo de agua, ignorando el reglamento y disminuyendo el suministro de la cuenca baja. Los "abajeños" crearon un comité de defensa que, tras inútiles negociaciones, intentó evitar la usurpación con las armas. También fueron inútiles las válvulas, llaves y contenciones construidas por las autoridades, que fueron dinamitadas pese a estar bajo custodia militar.

Con el tiempo, los chalcatzingas perdieron los sistemas de riego, por lo que solo pudieron mantener los cultivos de temporal y algunas tierras para el jitomate, que alimentaban con un costoso sistema de extracción de aguas subterráneas. Precisamente cuando el conflicto por los recursos demostraba que el desarrollo agrícola en la región no era del todo sustentable, llegó al pueblo el rumor de la Revolución Verde.

\subsection{El fin de las yuntas}

A principios de los sesenta, el país dejó de crecer a un ritmo milagroso. Por un lado, las necesidades del mercado interno se habían transformado, por lo que las exportaciones crecieron gradualmente. Por el otro, el campo había crecido de forma profundamente desigual como consecuencia de los selectivos programas de apoyo, que habían beneficiado a un pequeño grupo de terratenientes, mientras que la mayor parte de los campesinos, habitantes de tierras montañosas, áridas o semiáridas, donde las parcelas eran muy pequeñas, apenas producían suficiente para su consumo ${ }^{37}$.

Como consecuencia, México se había convertido en importador de alimentos, por lo que se decidió volver a regar los campos con recursos estatales. La estrategia tuvo dos frentes. El gobierno comenzó a intervenir directamente en la comercialización a través de la Compañía Nacional de Subsistencias Populares (CONASUPO) y el control del precio de los granos básicos. Simultáneamente, invirtió en la formación de un grupo de extensionistas

\footnotetext{
34 MASSEY D., et. al, Beyond Smoke and Mirrors: Mexican Immigration In An era of Economic Integration, Russell Sage Foundation, Estados Unidos, 2002.

35 HEWITT, C., La modernización de la agricultura mexicana 1940-1970, Siglo XXI editores, México, 1978, p.29.

36 WARMAN, A., ...Y venimos, op.cit.

37 HEWITT, C., "The "Green revolution" as history: the Mexican experience", en Development and change, Vol.5, pp.25-44, E.U., 1973, p.23.
} 
que se encargaría de la distribución de "paquetes tecnológicos", cuyas piezas clave eran las semillas mejoradas y los agroquímicos ${ }^{38}$.

Los paquetes se repartieron principalmente en las zonas de riego. Desde ahí, se propagaron -fragmentados y sin la presencia de extensionistas- hacia los ejidatarios de tierras de temporal. Salvador, conocido en el pueblo como La Coca, recuerda que los fertilizantes llegaron a través del boca a boca, de la voz de los cañaverales vecinos. Al probarlos, descubrieron que la diferencia era notable:

"Donde echaban fertilizante, una fichita, se veía verde, verde, verde la milpa.

Y donde no le echaban pues estaba verde, pero no igual [...]. Y hacíamos la comparación: tenemos una tierra, tenemos otra tierra, hagamos de cuenta que este es un niño y este es otro niño: si a este niño le damos otro bote de leche más, va a estar más gordito, va a estar más tranquilo y va a estar más resistente a las enfermedades; a este pobre no le damos su vasito de leche y va a estar más débil".

El uso de fertilizantes parecía revertir la pérdida de productividad de las tierras, por lo que los chalcas pensaron que a mayor cantidad, mejores resultados tendrían, "y así nos pasó en esa época, fuimos aplicando más y más y más y más", dijo La Coca.

A finales de la década llegó un segundo cambio: los tractores. Hasta ese entonces, la mayoría de los campos se araban con yunta. Muchos, como don Ilario, no tenían una, pero podían alquilarla por poco dinero, algunas horas de trabajo o una parte de la cosecha:

"Yo siempre soñé... bueno, sigo siendo pobre, pero en aquel tiempo más todavía, y lo que ansiaba yo era tener una yunta de bueyes propia. Siempre pedía prestado en Jantetelco. Y a la hora de cosechar, primero desgranaba y le daba yo lo de seis cargas de maíz, eso era lo de la paga de la yunta [...]. Incluso tiene como ocho días soñé que estaba yo unciendo la yunta, sí: sembrando. iBien que me vi con mis bueyes y a trabajar!"

Las yuntas que hasta hoy aparecen en los sueños de Ilario no pudieron competir con los tractores: "No niego que en el 67 se hayan exterminado las yuntas" -confesó La Coca"¿por qué vamos a preparar las tierras con yunta? Es más fácil meter el tractor y lo que hace una yunta en una semana, el tractor se lo hace en 3 horas. ¿Pues entonces, qué vamos a hacer al campo? ¿A perder el tiempo?".

Casi una década después, llegaron las semillas mejoradas y los pesticidas. La Coca recuerda que hicieron las mismas comparaciones y descubrieron que "eran resistentes a las plagas porque la semilla tenía más raíces, se profundizaba más, tenía más vida, en las resequedades la veíamos más frondosa". Las variedades locales perdieron su lugar ante este nuevo maíz, dejando en la gastronomía un vacío de sabores, que los chalcatzingas aún añoran. Como el del champurrado, que se preparaba con maíz "coloradito". "Y ese maíz recordó La Coca- nosotros aquí lo producíamos con ganas. ¿Y ahora? ¿Dónde está el maíz?".

${ }^{38}$ APPENDINI, K. y DE LUCA, M., Género y trabajo. Estrategias rurales en el nuevo contexto agrícola mexicano, FAO, Italia, 2006. 
Más tarde, los herbicidas liberaron a los chalcatzingas de la laboriosa tarea de desjegüitar, que requería el trabajo de varios peones. Además de reducir el empleo, los herbicidas se enfrentaron a la estructura tradicional de la milpa, ya que mataban a todas las hierbas que rodeaban al maíz, incluyendo al frijol y la calabaza. Aunque estos productos podían recuperarse si se sembraban después de "sellar" -aplicar los herbicidas-, esto implicaba un esfuerzo extra, que no necesariamente estaban dispuestos a hacer.

Como lo explica La Coca, la milpa estaba ahora sujeta a la lógica del coste/beneficio: "Donde hay digamos una hectárea, cuatro hectáreas de maíz, no es conveniente sembrar frijol porque las labranzas tienen que ser manuales. $Y$ se tiene que hacer el: "más o menos me voy a gastar tanto, cinco mil pesos por cuidar el maíz y la calabaza ¿es conveniente o no es conveniente?". Tiene uno que valorar, si no es conveniente pues yo no voy a trabajar, lo aprovecho en otra cosa para que pueda yo subsistir mejor y no hacer un trabajo en balde".

En los años setenta la agricultura comercial se había consagrado en el pueblo y, como recuerda Praxedis, convertido al campo en un buen negocio:

"Íbamos vendiendo cada ocho días, porque los carros pasaban comprando maíz. Pasaban y la gente decía: "ahí anda el maicero, que compra maíz". Y de eso nos manteníamos, el trabajo se acababa, pero teníamos el maíz, con eso nos manteníamos. Así todos le hacíamos, todo el pueblo. O sea que no sufríamos tanto, porque teníamos qué vender y había quién comprara.

Esto permitió el nacimiento de una época de relativa bonanza en la que, pese a seguir viviendo en condiciones de pobreza, los chalcas pudieron ampliar sus viviendas, invertir en educación y comprar otros bienes, como automóviles.

\subsection{Maíz y jitomate}

En aquellos años, me explicó Domingo B., todos en el pueblo tenían trabajo.

"Usted iba al campo y veía las huertas de jitomate, picante, pepino, frijol, cacahuate, ihabía de todo! Yo me acuerdo que iba a la escuela, salíamos y nos íbamos a cosechar cacahuate. Nos daba gusto, había empleo para los chiquillos [...]. Entonces había dinero para los chamacos, había empleo para todos, para los papás, para todos los hermanos, todos los chiquillos".

La región llegó incluso a ser un polo de atracción para migrantes de otros estados que, como recuerda Ilario, se empleaban temporalmente en sus campos: "muchos peones de Oaxaca, de Guerrero, venían a trabajar acá. Ellos, hacían de cuenta, como si fueran a Estados Unidos".

En este contexto, no resulta sorprendente que los chalcas se vieran poco tentados por la migración internacional. En aquellos años la migración interna comenzó a volverse habitual, pero era una práctica que se compaginaba con la territorialidad agraria. En la mayoría de los casos no implicaba un desplazamiento definitivo, ya que los chalcas podían ir y venir de sus otros centros de trabajo en el mismo día, o se realizaba en épocas en las que el campo requería menos atención. Quienes se iban por periodos prolongados eran quienes tenían 
menor participación en las labores agrarias, principalmente mujeres, todavía niñas, que se empleaban como trabajadoras domésticas en la Ciudad de México.

Aunque algunos fueran y vinieran, era el campo el que, como me explicó Inés, articulaba las rutinas y reunía al pueblo:

"Mucha gente trabajando, demasiada gente. A la hora de la comida, que es a las doce o a la una, va la esposa a dejarle de comer al marido, se cruzaban las esposas, los señores. Trabajando aquí uno, allá otro, se veía muy bonito. Ahora, haga de cuenta, como usted está aquí y ahí él está trabajando, su vecino. Ahí está trabajando su otro vecino con su yunta. Allá está otro vecino. O sea, daba gusto sembrar".

En el calendario, cada fase del cultivo del maíz estaba marcada con una festividad en la que, como me explicó La Coca al hablar de la fiesta de San Miguel Arcángel, demostraban su amor a la tierra a través de la religiosidad: "los que creen en dios y tienen mucho afecto al campo a través de dios, le ponen [flores y cruces] a San Miguel Arcángel, porque es el santo que anda combatiendo el mal, más bien el mal en relación de que no haya abundancia".

Gracias a la actividad en el campo, recordó Humberto, el paisaje del pueblo era otro: "se veía el campo lleno de jitomates, tomates, de lo que sembraban. A mí me gustaba, la hierba, el olor, el paisaje estaba muy bonito". Aquellos colores se complementaban con los de la vegetación de los cerros, donde los chalcas pasaban su infancia pastoreando vacas y chivos, y los de los huertos, bajo cuyos árboles se resguardaban del sol al sabor de una pera o una chirimoya.

Otro lugar emblemático en las memorias de aquel Chalca es el Amatzinac que todavía fluía abundante, pese a los cultivos de los arribeños, llevando manjares como el atolocate "parecido al ajolote, casi igual. Muy sabroso ese pescado. En tamal, iuf, que rico!, en mole verde iuf, que rico!, en chilito verde iuf, no hombre!", evocó Praxedis casi salivando.

Además, era fácil encontrar ojos de agua y remanentes del río que los chalcas utilizaban para regar, beber y refrescarse: "Mis abuelitas tenían [...] un ranchito y tenían muchas plantas... ipero el agua! -suspiró Cirila- Haz de cuenta que afuera, por una barranquillita, pasaba el agua, y habían rascado un pocito, que yo veía que mis tíos, mi mamá o ellos, la sacaban agachados. iAsí nada más! Se agachaban para agarrar el agua. El agua tan dulce, tan fresca, limpiecita".

Aquel sencillo paraíso comenzó a desvanecerse cuando el gobierno desarmó pieza por pieza el motor que a lo largo del siglo XX había mantenido a flote a la economía agrícola.

\section{Nacimiento del Chalcatzingo migrante}

A principios de los ochenta, la recesión económica que se ocultaba bajo el manto de un Estado generoso y protector, fue desvelada por una crisis mundial, que provocó que el precio del petróleo se desplomara y las tasas de interés a los préstamos adquiridos en el mercado internacional se triplicaran, dejando al país corto de recursos y con una deuda que era incapaz 
de pagar ${ }^{39}$. A cambio del apoyo en la gestión de la deuda, el FMI impuso a México algunas medidas que facilitarían su inserción en el creciente sistema financiero global.

Las medidas fueron bien recibidas por el gobierno mexicano, que en aquel momento integraba en sus filas a un grupo de jóvenes economistas que proponían una reforma neoliberal. Desde su punto de vista, el excesivo gasto en el campo -que entonces absorbía alrededor del $16 \%$ del presupuesto federal-, había generado un agro dependiente, poco competitivo e incapaz de promover el desarrollo ${ }^{40}$. La solución era reducir la inversión y el control estatal para permitir la libre circulación del capital y la competencia. Así, afirmaban, se abriría paso a una industria capaz de competir en el mercado internacional.

Con este fin se formuló una nueva política agrícola en torno a cuatro pilares: la desaparición de subsidios, barreras arancelarias y precios de garantía; la reestructuración de las instituciones y paraestatales destinadas al campo; la reforma del artículo 270 de la Constitución para permitir la compraventa de tierras; y la apertura al mercado exterior.

\subsection{La carestía}

Con los primeros recortes presupuestarios, los subsidios, apoyos a la comercialización y créditos rurales se redujeron $67 \%$ entre 1982 y $1989^{41}$. Para los chalcatzingas, los problemas comenzaron precisamente en esa época. Sin embargo, según recuerdan, su origen no fueron las reformas, sino una fuerte sequía: "no hubo nada, nada en el campo afirmó Domingo B. No hubo cosecha para nadie. Inolvidable. Fue en el 85". O, como lo explicó Luis, un cambio de tiempo tras el que la agricultura fue haciéndose cada vez más difícil:

"Normalmente dejó de llover en el 85. De años anteriores llovía normalmente, en el tiempo de las cosechas, pero de ahí para acá ha ido fallando ya siempre y se ha ido poniendo más difícil [...]. De ahí para acá empezó a cambiar el tiempo".

Aunque después de la sequía las Iluvias regresaron a Chalcatzingo, parecían estar en una nueva sintonía, ajena al ritmo del calendario agrícola:

"Ya el temporal no viene como antes -afirmó Olegario- está todo distorsionado:

llueve cuando no debe de llover y cuando debe de llover no llueve. Luego a veces empieza a llover [imita el sonido de lluvia] y todos se alocan ahí a arar sus tierras, a sembrar; luego, cuando en dos semanas ya está la plantita y ya no llueve, todo se marchita, se seca y ya no da".

Para quienes sembraban jitomate, como Parexdis y La Coca, el problema no estaba en el agua, sino en el aire, que llevó al pueblo las plagas que pusieron fin a los tiempos de abundancia:

"Llegó el tiempo que aquí empezó a caer una enfermedad en dónde la planta de jitomate, llegando a un tamaño de unos 40-50 cm., la hojita se empezaba

\footnotetext{
39 HEWITT, C., "Ensayo sobre los obstáculos al desarrollo rural en México. Retrospectiva y prospeciva", en Descatos, no. 25, septiembre-octubre, pp.79-100, CIESAS, México., 2007.

40 ORDOÑEZ, G., "Eficacia y equidad en el combate a la pobreza en México", en Valencia L (coord.), Los dilemas de la política social, ¿cómo combatir la pobreza?, Amaroma ediciones, México , 2000, p.124

${ }^{41}$ APPENDINI, K. y DE LUCA, M., Género y trabajo, op.cit, p. 5
} 
a enchinar; una enfermedad que nunca la pudimos combatir. Entonces esa enfermedad vino a dar origen de que todos los que sembrábamos jitomate dejáramos de sembrar, porque ya no era costeable".

Aquella plaga -recordó La Coca- fue extendiéndose por el oriente de Morelos: "Primero les tocó a Tetelilla, Tepalcingo y todo eso, decíamos "es que no son buenos productores" y la verdad es que no es cierto, cuando a nosotros nos tocó, ya decíamos "¿Qué nos pasó?". Analizamos las tierras y todas estaban normal, el problema era el aire. Por eso decimos que nos estamos acabando por los herbicidas y fungicidas que aplicamos".

Los agroquímicos terminaron gradualmente con las plantas que solían rodear a los cultivos, como calabaza, frijol, chile y otras yerbas que ocupaban un lugar importante en la dieta de los chalcas. Esta pérdida de flora, como me explicó Ilario, afectó a otros productos regionales:

"La joden los herbicidas, ese es el que acaba la tierra. Hoy hasta se quejan los que tienen sus avispas de miel, como ya todos fumigan los carriles, ya ni sale la flor de acahual -una flor grandota, no sé si la conozca, amarilla-, pues de ahí dicen que chupa la miel y de la zetilla; pero como fumigan todos los campos, las mieleras se quejan de que ya no producen la misma miel las pobres avispas".

"Había bastante, las cosechas eran muy buenas. Ahora ya no, porque, por ejemplo, todos los que siembran el sorgo, pues fumigan y se acaba esa yerba", me confirmó Raquel, una de las pocas mieleras que quedan en el pueblo. "Entonces nada más donde no siembran, o ahorita ellas se van también por las flores de los árboles grandes [...]. Pero a veces sí ya está crítico, porque allá abajo todos los del sorgo limpian sus carriles".

Por otro lado, los fertilizantes generaron en la tierra una especie de adicción. Así me lo explicó La Coca:

"Si no aplicamos una porción más de fertilizante, si no aumentamos más, la planta ya no da el mismo resultado. Comparación: si yo hace una semana me comía tres tortillas y dos platos de guisado y con eso era más que suficiente, a la siguiente semana ya debo de comerme dos y medio para tener yo las mismas resistencias orgánicas para poder desempeñar mis labores que hago diario; a la tercera semana debo comerme tres platos y cuatro tortillas, porque ya necesito más. Es como el que se droga".

Cuando la desaparición de los subsidios puso en evidencia la dependencia de los agricultores hacia los productos introducidos por la Revolución Verde, me explicó Tomás, sobrevino la "carestía": "cuando me casé, sembrábamos jitomate, chiles, pepinos, maíz. Eso hacíamos, pero por cosas de la carestía llegó el día en el que era ya un poquito más complicado levantar la siembra". La "carestía" - me respondió cuando le pregunté a qué se refería- llegó cuando "el producto que nosotros hacíamos valía menos que los fertilizantes".

Para a hacer frente a la carestía, los pueblos de la cuenca alta del Amatzinac construyeron 
viveros que regaban con un sistema de mangueras que se alimentaban directamente del río. "Fue entonces -aseguró don Domingo- cuando nos quedamos huérfanos". Los chalcas comenzaron a notar la desaparición de los ojos de agua y remanentes. El agua desapareció de aquellos lugares en los que antes podía cogerse con las manos "se fue yendo -recordó Cirila- y ya le poníamos un hilito y después una cuerda". También los huertos, me explicó, fueron desapareciendo, como si fueran víctimas de una epidemia lenta y letal ante la que no supieron cómo reaccionar: "estábamos tontos, no plantamos más árboles, porque se fueron secando de uno en uno".

Paralelos a esta crisis, continuaban los cambios en la política agraria del país. México dio los primeros pasos hacia la apertura comercial en 1986, al suscribir el General Agreement on Tariffs and Trade (GATT, por sus siglas en ingles). En 1992 firmó el Tratado de Libre Comercio con América del Norte (TLC), que fijó un plazo de 15 años para la desaparición de todas las barreras arancelarias. Tras la firma del TLC, se homologaron los precios internos y externos, pese a que los costes de producción eran menores en Estados Unidos, donde sí se mantuvieron los subsidios. Como consecuencia, entre los años 1990 y 2000, las importaciones crecieron a una tasa anual de $12 \%{ }^{42}$.

"El 94 fue el último año que sembré", aseguró Tomás y después me explicó los motivos:

"Fueron dos cosas. Un poquito que el campo es muy bonito, pues, pero yo no tengo tierras. Yo rentaba para sembrar y decidí hacerme a un lado porque en los últimos dos años que todavía me animé a sembrar, sembrábamos con mi papá, en uno de los años me acuerdo que nos endrogamos. Vendimos una casa porque -dijo entre risas que se adivinan nerviosas- no salió nada, no salió nada y tuvimos que venderla [...]. Y todavía así nos animamos a volver a sembrar y ya las cosechas ya salían, pero regularmente cuando hay mucho producto se abaratan. A veces las tierras se daban bien, pero iba uno a vender y el mercado daba una tristeza: ir, llevar, en este caso nosotros llevábamos jitomates, y con tanto esfuerzo se levantan ¿verdad?, tanto sacrificio e iba uno allá y a uno le compraban... estaba muy barato, pues".

A diferencia de los otros entrevistados, que no hicieron referencia a los acontecimientos nacionales de la época, Praxedis achacó el problema directamente al TLC:

"Hasta que entró el libre comercio, dejamos de sembrar maíz. ¿Para qué vamos a sembrar maíz si ya no se vende? Ni cacahuate. Ya nada, pues, ese año en el campo ya nada se vendió: ni el jitomate ni el maíz ni el cacahuate. Eran las siembras fuertes de acá, pero desde que entró el libre comercio ya no se vendía nada. Entonces la gente se empezó a ir, los muchachos, pues, para el norte".

La desarticulación de la vida agrícola dejó sin trabajo a cientos de chalcatzingas. Fue entonces, me explicó Domingo B., cuando decidieron marcharse:

42 MAGAÑON, B. y FRITSCJER, M., "La agricultura mexicana y el TLC: el desencanto neoliberal", en Debate Agrario, No. 37, 2004, pp. 183-210, p. 190. 


\begin{abstract}
"Antes nadie se iba para el norte, porque le digo que había empleo. Y una vez que se acabó eso pues ya todos se empezaron a ir, a ir, a ir. Entonces empezaron a irse, a irse [...]. Mucha gente empezó a emigrar a los Estados Unidos, pero la misma necesidad es lo que obliga [...] Porque si se queda uno aquí, ¿quién le va a dar trabajo aquí? Porque aquí en el pueblecito no hay trabajo, son pueblos chicos, no hay fábricas..."
\end{abstract}

A lo largo de la década de los noventa, el número de migrantes morelenses en Estados Unidos pasó de 97.000 a 244.000 .43 No existen datos oficiales sobre la emigración en Chalcatzingo, pero los testimonios de los chalcas permiten suponer que el pueblo siguió un patrón similar.

A mediados de los noventa, en el pueblo había ya un sistema de redes que permitía a cualquiera atravesar la frontera, generalmente de manera clandestina, y encontrar trabajo al otro lado. La más sólida de ellas, permitió que decenas de chalcas encontraran su lugar en Estados Unidos como caballerangos en clubs de polo. Gracias a este particular nicho de trabajo, muchos pudieron establecerse de manera indefinida en el norte; los más afortunados cuentan incluso con visas que les permiten visitar su pueblo periódicamente.

\title{
5. ¿Migración ambiental?
}

A manera de conclusión, propongo analizar el caso de Chalcatzingo a la luz de la perspectiva territorial. Más que clasificar los motivos de la migración chalcatzinga, mi objetivo es mostrar cómo puede contribuir este enfoque al estudio de las migraciones $y$, particularmente, a la reflexión sobre la migración ambiental.

Como lo muestran las memorias de la tierra, los chalcatzingas consideran que los problemas ambientales fueron un factor determinante en el abandono de la agricultura y, como consecuencia, en su migración. Los problemas descritos en sus testimonios coinciden con los diagnósticos ambientales de la región que -como ya he mencionado- señalan que los principales factores de riesgo son, precisamente las sequías interestivales, la escasez de agua y la inocuidad.

No cabe duda de que estos problemas existen ni de que han afectado adversamente su calidad de vida. Sin embargo, la perspectiva territorial ofrece algunos elementos de análisis que vale la pena considerar antes de afirmar que los problemas ambientales detonaron la migración en Chalcatzingo.

En primer lugar, llama la atención la forma en que los problemas ambientales aparecen en las memorias de la tierra, como una crisis súbita y catastrófica, que terminó con el agua, las tierras, los árboles y las cosechas. Esta crisis coincide con asombrosa exactitud con el reajuste estructural de los años ochenta. Incluso si la mayoría de los chalcas no achacan sus problemas en el campo a los cambios en el mercado, en sus narraciones los problemas

\footnotetext{
43 LOZANO, F. y RIVERA, L., Las dinámicas de las trayectorias y las redes de migrantes en contextos urbanos y rurales, ponencia para el Segundo Coloquio Internacional sobre Migración y Desarrollo: Migración, transnacionalismo y transformación social, México, 2006 consultada en http://www.estudiosdeldesarrollo.net/coloquio2006/ docs2006/18606.pdf, 3 de enero de 2013.
} 
ambientales se entrelazan ineludiblemente con los económicos: la sequía y la apertura del mercado, las plagas y el abaratamiento de sus productos, el agotamiento de las tierras y el encarecimiento de los agroquímicos.

Desde mi punto de vista esta confluencia de las crisis debe ser entendida como una forma de representar el pasado en la que se pone de relieve un fenómeno poco considerado por los estudios ambientales: el hecho de que la forma en que los sujetos y los grupos perciben el ambiente y actúan sobre él no responde únicamente a factores objetivos, sino que está fuertemente influida por su experiencia y por el marco sociocultural que los envuelve ${ }^{44}$.

Esto no quiere decir que los problemas ambientales sean un asunto de percepción, sino que la forma en que los percibimos depende en buena medida de cómo éstos nos afectan. Y la forma en que nos influyen está a su vez condicionada por otros factores, como la situación económica y qué tan directamente dependamos de nuestro medio ambiente para sobrevivir.

En este orden de ideas, podemos pensar que la manera en que los chalcas recuerdan los problemas ambientales que provocaron el abandono de la agricultura está marcada por la elevada vulnerabilidad en la que se encontraban tras la implementación de las políticas neoliberales. Al tener que hacer frente, empobrecidos y sin subsidios, a los avatares del clima y el mercado, la lluvia comenzó a parecerles más escasa y las milpas menos resistentes. La tierra sufrió entonces una doble sequía: una física, provocada por la falta de agua; la otra simbólica, producida porque, en aquella coyuntura, sembrar dejó de tener sentido. De esta forma, la perspectiva territorial pone en evidencia que, en casos como el de Chalcatzingo, separar lo económico de lo ambiental es segmentar la realidad, reduciendo a simple lo complejo ${ }^{45}$.

En segundo lugar, creo que esta perspectiva pone de relieve que la migración en Chalcatzingo no debe comprenderse solamente como la consecuencia de una crisis agraria, sino como un cambio de territorialidad.

A lo largo del siglo XX la vida agrícola de Chalcatzingo estuvo apuntalada por un aparato estatal que no consiguió -como pretendía el Estado posrevolucionario- sacar a los campesinos de la pobreza ni hacer del campo el eje del desarrollo nacional, pero sí contribuyó al crecimiento de una economía agrícola basada en el ejido, que se convirtió en el eje de la relación entre las sociedades rurales y su territorio. Mientras aquella estructura estuvo en pie, los chalcatzingas enfrentaron las frecuentes crisis ambientales y económicas echando mano de otras estrategias, como extender las tierras de cultivo, adaptar su producción al mercado o incorporar nuevas agrotecnologías. Cuando las políticas neoliberales eliminaron el potencial económico de aquel eje, la territorialidad agrícola comenzó a desarticularse.

Primero, el campo dejó de ser la principal fuente de sustento, después, perdió su importancia social y cultural. Entonces, los chalcatzingas, que habían resistido en sus tierras

\footnotetext{
${ }^{44}$ GERRISTEN, P., et.al., "El mundo en un espejo. Percepciones campesinas de los cambios ambientales en el Occidente de México", en Economía, Sociedad y Territorio, Vol. IV, núm. 14, julio-diciembre, 2003, pp.253-278.

45 MORIN, E., Introducción al pensamiento complejo, Editorial Gedisa, Barcelona, 2007.
} 
pese a la pobreza, la experiencia de los Braceros y su familiaridad con la migración interna, se incorporaron al creciente flujo migratorio México-Estados Unidos, que debe ser entendido como una suma de factores de atracción y expulsión ${ }^{46}$.

Al poco tiempo, se consolidaron las redes que permitieron que los chalcas continuaran yéndose, enviando remesas, volviendo y creando nuevos proyectos en su pueblo. Así, emergió una nueva territorialidad, construida en torno a un nuevo eje económico: la migración. Esta reconfiguración territorial pone en evidencia que los problemas ambientales difícilmente podrían considerarse el principal detonante de la migración en Chalcatzingo, que debe ser comprendida como resultado de un proceso mayor, que fisuró las raíces de las sociedades rurales en México.

Como lo demuestra el estudio del caso de Chalcatzingo, la perspectiva territorial ofrece la posibilidad de hacer un análisis complejo, que permite incorporar a los problemas ambientales, pero dimensionando su importancia y relación con otros factores de expulsión. Este tipo de estudios, que anteponen el análisis territorial a las teorías homogeneizantes aquellas que asumen una conexión lineal entre el deterioro ecológico y la migración-, podrían contribuir a esclarecer la pertinencia epistemológica de la noción de migración ambiental.

\section{Bibliografía}

APPENDINI, Kirsten y DE LUCA, M., Género y trabajo. Estrategias rurales en el nuevo contexto agrícola mexicano, FAO, Italia, 2006.

ARANA, Raúl., "Classic and Postclassic Chalcatzingo", en GROVE, David, (ed), Ancient Chalcatzingo, University Texas Prees, E.U., 1987, pp. 387-399

AUTOR, 2015.

ÁVILA, Héctor, Aspectos históricos de la formación de regiones en el estado de Morelos: desde sus orígenes hasta 1930, CRIM-UNAM, México, 2001.

Conapo, Conteo nacional de población y vivienda 2010, en www.conapo.gob.mx, consultado 5 de mayo 2013.

DE CERTEAU, MICHEL, La invención de lo cotidiano. 1 Artes de hacer, Universidad IberoamericanaITESO, México, 2000

DURAND JORGE y MASSEY Douglas, "Clandestinos. Migración México-Estados Unidos en los albores del siglo XXI", Universidad Autónoma de Zacatecas-Porrúa, México, 2003.

EL-HINNAWI, Essam, Environmental Refugees, United Nations Environment Programme, Nairobi, 1985, p.4.

GERRISTEN, Peter, MONTERO, María y FIGUEROA, Pedro, "El mundo en un espejo. Percepciones campesinas de los cambios ambientales en el Occidente de México", en Economía, Sociedad y Territorio, Vol. IV, núm. 14, julio-diciembre, 2003, pp.253-278.

GILLY, Adolfo, La revolución interrumpida, Era, México, 1971.

GUERRERO, Manuel Anotnio, Suelos agropecuarios del estado de Morelos, CRIM, México, 1993.

HALBWACHS, Maurice, La memoria colectiva, Prensas Universitarias de Zaragoza, España, 2004

HALBWACHS, MAURICE., Los marcos sociales de la memoria, Antrhopos, Barcelona, 2004

HEWITT, Cynthia, "Ensayo sobre los obstáculos al desarrollo rural en México. Retrospectiva y prospeciva", en Descatos, no. 25, septiembre-octubre, pp.79-100, CIESAS, México.

HEWITT, Cynthia, "The "Green revolution" as history: the Mexican experience", en Development and change, Vol.5, pp.25-44, E.U., 1973.

HEWITT, Cynthia, La modernización de la agricultura mexicana 1940-1970, Siglo XXI editores, México, 1978.

HUGO, Graeme, Migration, development and environment, Draft paper for Research Workshop on Migration and the Enviornment: Developing a Global Research Agenda, 2008, Germany,

\footnotetext{
46 MASSEY, D., et. al., Worlds in Motion. Understanding International Migration at the End of the Millennium, Oxford: Clarendon Press, UK, 1998.
} 
consultado en http://www.populationenvironmentresearch.org, 22 de enero de 2011.

HUNTER M.L., LUNA J., NORTON R. , "Enviromental Dimensions of Migration", en Annual Review of Sociology, Vol.41, octubre de 2014, pp.377-397

INEGI, Archivo histórico de censos en http://www3.inegi.org.mx/sistemas/productos/default. aspx $? c=265 \& s=$ inegi\&upc $=702825003963 \& p f=P r o d \& e f=\& f=2 \& c l=0 \& t g=0 \& p g=0, \quad$ consultado el 3 de marzo de 2013

LEFEBVRE, Henri, The production of space, Blackwell Publishing, UK, 1977.

LINDÓN, Alicia, De las geografías constructivistas a las narrativas de vida espaciales como metodologías geográficas cualitativas, en Revista ANPEGE, No. 4, pp.3-27, Brasil, 2008, p.19

LOZANO, Fernando y RIVERA, Liliana, Las dinámicas de las trayectorias y las redes de migrantes en contextos urbanos y rurales, ponencia para el Segundo Coloquio Internacional sobre Migración y Desarrollo: Migración, transnacionalismo y transformación social, México, 2006 consultada en http://www.estudiosdeldesarrollo.net/coloquio2006/docs2006/18606.pdf, 3 de enero de 2013.

MAGAÑON, Boris y FRITSCHER, Magda, "La agricultura mexicana y el TLC: el desencanto neoliberal", en Debate Agrario, No. 37, 2004, pp. 183-210, p. 190.

MASSEY Douglas, et. al, Beyond Smoke and Mirrors: Mexican Immigration In An era of Economic Integration, Russell Sage Foundation, Estados Unidos, 2002

MASSEY, Doreen, "La filosofía y la política de la espacialidad: algunas consideraciones", en Arfuch (Comp.), Pensar este tiempo: espacios, afectos, pertenencias, Paidós, México, 2005, pp. 102128, p. 109.

MASSEY, Douglas, ARANGO, Joaquín, HUGO, Graeme, KAOUACI, Ali, PELLEGRINO, Adela y TAYLOR, Edward, Worlds in Motion. Understanding International Migration at the End of the Millennium, Oxford: Clarendon Press, UK, 1998.

MORIN, Edgar, Introducción al pensamiento complejo, Editorial Gedisa, Barcelona, 2007.

NAWROTZKI R., HUNTER L., RUNFOLA D. y RIOSMENA F., "Climate change as a migration driver from rural and urban Mexico", en Environmental Research Letters, Vol. 10, noviembre de 2015, pp. 1-9

Organización Internacional para las Migraciones OIM, Nonagésima cuarta reunión. Nota para las deliberaciones: La migración y el medio ambiente, MC/INF/288, 2007, p.3.

OSWALD, Úrsula. y TRUJILLO, Fernando, "Del Holoceno al Antropoceno: evolución del ambiente de Morelos", en Crespo (Dir), Historia de Morelos, tierra, gente, tiempos del Sur, Morales LG (Coord), tomo I, Historiografía, territorio y región, UAEM/ LI Legislatura del Congreso del Estado de Morelos, México, 2012.

RENAUD Fabrice, BOGARDI Janos, DUN Olivia y WARNER Koko, "Control, Adapt or Flee - How to Face Environmental Migration?", InterSecTions, 5, 2007, Bonn: United Nations University Institute for Environment and Human Security (UNU-EHS) consultado en www.un.edu, 3 de junio de 2011.

SAGARPA, Informe del diagnóstico rural del estado de Morelos, México, 2014, consultado en http:// www.fao-evaluacion.org.mx/pagina/documentos/sistemas/eval2014/resultados2014/PDF2/ MOR/Diagnostico_Rural_MORELOS.pdf, 3 de diciembre de 2017.

Shurke, Astri,Pressure points: environmental degradation, migration and conflict. Workshop on Environmental Change, Population Displacement, and Acute Conflict, June 1991. Ottawa: Peace and Conflict Studies Program, University of Toronto and The American Academy of Arts and Sciences, Cambridge, MA., 1993.

WARMAN, Arturo, ...Y venimos a contradecir. Los campesinos de Morelos y el estado nacional, Ediciones de la casa Chata, México, 1976, p.217.

WERTSCH, James, DEL RÍO Pablo, ÁLVAREZ Amelia, La mente sociocultural: aproximaciones teóricas y aplicadas, Fundación Infancia y Aprendizaje, España, 1997

YORY, Carlos (2005), "Del espacio ocupado al lugar habitado: una aproximación al concepto de topofilia", en Serie ciudad y hábitat, Colombia, No.12.

Zavella, Patricia, I'm Neither Here Nor There: Mexican's Quotidian Struggles with Migration and Poverty, Duke University Press, EU, 2011. 


\section{RELACIONES INTERNACIONALES}

Revista académica cuatrimestral de publicación electrónica Grupo de Estudios de Relaciones Internacionales (GERI) Universidad Autónoma de Madrid, España

www.relacionesinternacionales.info

ISSN 1699 - 3950

ff facebook.com/RelacionesInternacionales

twitter.com/RRInternacional 